\title{
Optimization of SSF parameters for natural red pigment production from Penicillium purpurogenum using cassava waste by central composite design
}

\author{
C. Padmapriya* and R. Murugesan \\ Dept. of Agric. Microbiology, Tamil Nadu Agricultural University, Coimbatore- 641003 (Tamil Nadu), INDIA \\ *Corresponding author. E-mail: agri.padma@gmail.com
}

Received: January 13, 2016; Revised received: July 12, 2016; Accepted: August 27, 2016

\begin{abstract}
Pencillium purpurogenum 8904.12, a red pigment producer, was isolated from soil screened and selected based on the pigment production. The pigment production by P.purpurogenum was optimizedby using factorial design and Response Surface Methodology (RSM) in SSF. Cassava waste is a low cost and nutrient rich substrate used in this study as a substrate. RSM based central composite design was employed to obtain best combination of substrate concentration, inoculum volume, incubation time, initial moisture and initial $\mathrm{pH}$. By the point prediction tool of Design-Expert 8.0, the optimum values of the factors for maximum red pigment production were determined. Under the optimized conditions (substrate concentration $10 \mathrm{~g}$, inoculum volume $5 \mathrm{ml}, 15$ days incubation time, $50 \%$ initial moisture and initial $\mathrm{pH}$ of 6 ), the red pigment yield was 28.33 colour value units $/ \mathrm{g}$ of dry fermented substrate which agreed closely with the predicted yield. The model showed that the value of $R^{2}(0.9936)$ was high and $p$ value of interaction of variance was $<0.0001$. Hence the model can be said to be of highly significant. A significant Increase in red pigment production was achieved using RSM. Thus, utilization of cassava waste for red pigment production in this study could provide the most effective use of cassava resource, and lead to technology of development for its further utilization and value addition.
\end{abstract}

Keywords: Cassava waste, Penicillium purpurogenum, Red pigment, Response surface methodology, Solid state fermentation

\section{INTRODUCTION}

Pigments, which are either natural or synthetic, play an important role in food, textile and pharmaceutical industry as colourants. Synthetic red pigments such as azorubin or tartrazin cause allergic reactions (Fabre et al., 1993) and C- red having carcinogenic and tetragenic effects (Marlin et al., 1987). The scrutiny and negative perceptions of synthetic food pigments by the modern consumer have given rise to a strong interest in natural colouring alternatives for human safety and environmental conservation (Dufosse, 2006).

Natural pigments can be obtained from two major sources, plants and microorganisms. The accessible authorized natural pigments from plants have numerous drawbacks such as instability against light, heat or adverse $\mathrm{pH}$, low water solubility and often nonavailability throughout the year. The later are of great interest owing to the stability of the pigments produced and the availability of cultivation technology (Parekh et al., 2000). Monascus species are well known to produce pigments like monascorubrine, rubropunctatine (Juzlova et al., 1996 and Pattanagul et al., 2007). On the other hand, Monascus-derived pigments contain citrinin, and the production of mycotoxin limits the use of Monascus as a producer of food colourants (Liu et $a l ., 2005)$. Therefore, it is interest to search for alterna- tive pigment producing organisms. The production of Monascus-like red pigments from Penicillium strains have been reported recently. These pigments have a potential use in the food industry because they are not associated with citrinin production (Mapari et al., 2008). However, the high cost of the current liquid culture-based fermentation technology has limited the industrial use of red pigment from Penicillium purpurogenum. There is a growing need for low cost production of natural pigments or colouring agents.

Solid state fermentation (SSF) has emerged as an effective alternative for liquid culture-based fermentation technology. The substrates used in SSF supply the basic nutrients to the microorganisms and serve as an anchor for the cells (Babitha et al., 2007). Interestingly, recent studies report that SSF provides a more adequate habitat for fungi, resulting in high pigment production in a relative low-cost production process when agro-industrial wastes are used as substrate (Velmurugan et al., 2011). The starch manufacturing industries from cassava, which also produce the solid wastes, from the peelings and the screening of starch slurry before sedimentation, called as cassava waste. Annual production of cassava waste in India is 380 kilo tonnes and processing of one tonne of cassava roots gives $151 \mathrm{~kg}$ of peelings and $51 \mathrm{~kg}$ of cassava waste. Cassava waste is a highly economical substrate 
Table 1. Showiwng process variables and their levels in the design of experiments.

\begin{tabular}{|c|c|c|c|c|c|c|c|}
\hline \multirow{2}{*}{ Factors } & \multirow{2}{*}{ Coded symbols } & \multicolumn{5}{|c|}{ Coded levels } & \multirow{2}{*}{ Interval of variation } \\
\hline & & $-\alpha$ & -1 & $\mathbf{0}$ & +1 & $\mathbf{A}$ & \\
\hline Substrate concentration $(\mathrm{g})$ & $S$ & 5.24 & 8 & 10 & 12 & 14.75 & 2 \\
\hline Inoculum volume (ml) & $I$ & 0.75 & 2 & 4 & 6 & 8.75 & 2 \\
\hline Incubation time (days) & $T$ & 3.10 & 10 & 15 & 20 & 26.89 & 5 \\
\hline Initial moisture (\%) & $M$ & 2.43 & 30 & 50 & 70 & 97.56 & 20 \\
\hline Initial pH & $P$ & 3.62 & 5 & 6 & 7 & 8.37 & 1 \\
\hline
\end{tabular}

for SSF and it contains complex of starch, cellulose, hemicelluloses, pectin, fiber and protein which promote the fungal growth and thereby increase the pigment yield.

Optimization of process condition is one of the most critical stages in the development of an efficient and economic bioprocess (Karuppaiya et al., 2009). The conventional one-factor-at-a-time approach of optimization is not only tiresome but also ignores to merge interaction of each factor. One of the most common optimization used in last two decades is the Response Surface Methodology (RSM). RSM can be used to evaluate the relative significance of several affecting factors and it is an empirical statistical modelling technique employed for multiple regression analysis using quantitative data obtained from properly designed experiments to solve multivariable equations simultaneously (Haltrich et al., 1993; Prapulla et al., 1992). RSM studies help to determine the accurate optimum values of test variables on the basis of a limited number of experiments. There are various advantages in using statistical methodologies in terms of rapid and reliable short listing of process conditions, understanding interaction among them, and a tremendous reduction in total number of experiments, resulting in saving time, glassware, chemicals and manpower (Karuppaiya et al., 2010). In spite of various advantages, statistical designs have been applied to only limited number of aerobic submerged and solid state fermentation processes deal with a large number of variables, and there are several reports on the application of RSM for the production of primary and secondary metabolites through microbial fermentation (Karuppaiya et al., 2009). Present study was undertaken with the objective of using RSM to optimize the process parameters for production of red pigment from $P$. purpurogenum employing SSF using cassava waste.

\section{MATERIALS AND METHODS}

Microorganism: The fungus used in this study was isolated from soil, collected from Parambikulam tiger reserve, India. The red pigment producing fungi was identified as Penicillium purpurogenum and certified through Indian Type Culture Collection (ITCC), Division of Plant Pathology, IARI, New Delhi for confirmation. The ITCC accession number obtained was 8904.12 . The strain was maintained by routine weekly transfer, under aseptic conditions to Potato Dextrose
Agar (PDA) slants and stored at $4^{\circ} \mathrm{C}$ after being incubated at $30^{\circ} \mathrm{C}$ for 5-7 days.

Preparation of inoculum: Pure culture of $P$. purpurogenum from PDA slants was transferred into $250 \mathrm{ml}$ Erlenmeyer flasks containing $100 \mathrm{ml}$ of the growth medium. After cultivation of 2-3 days, spores were collected with $5 \mathrm{ml}$ of sterilized water and the spore suspension collected was used as inoculum preparation.

Substrate and solid state fermentation: Dried cassava waste was obtained from sago factory, Salem, Tamil Nadu. The optimal level of dried cassava waste substrate was studied by varying the amount of substrate was placed in $250 \mathrm{ml}$ Erlenmeyer flask and a nutrient solution $(3 \mathrm{ml})$ containing $(\mathrm{g} / \mathrm{L}): \mathrm{KH}_{2} \mathrm{PO}_{4}(2)$, $\mathrm{NH}_{4} \mathrm{NO}_{3}$ (5), $\mathrm{NaCl}$ (1) and $\mathrm{MgSO}_{4} \cdot 7 \mathrm{H}_{2} \mathrm{O}$ (1) was added by adjusting different $\mathrm{pH}$ (2 to 9 ). Initial moisture content was adjusted with distilled water. Flasks contents were mixed thoroughly, autoclaved at $121^{\circ} \mathrm{C}$ for $20 \mathrm{~min}$, and cooled to room temperature. The flask was inoculated with $2 \mathrm{ml}$ spore suspension containing $6 \times 10^{5}$ spores $\mathrm{ml}^{-1}$ of $P$. purpurogenum and incubated at $30^{\circ} \mathrm{C}$ for 15 days. While the temperature and concentration of nutrient solution factors were kept constant.

Extraction and quantification of pigment: The fermented CPW substrate was extracted with $5.0 \mathrm{ml}$ of 90 per cent methanol per $g$ of dry fermented substrate (gdfs). The mixture was placed on a rotary shaker at $200 \mathrm{rpm}$ for $1 \mathrm{~h}$ and allowed to stand for $15 \mathrm{~min}$. Filtration was done through Whatman No. 1 filter paper and the extracted pigment was quantified by measuring $\mathrm{OD}$ at $500 \mathrm{~nm}$. Pigment yield was expressed as Colour Value Units per $\mathrm{g}$ of dry fermented substrate (CVU gdfs $^{-1}$ ) (Babitha et al., 2007; Tseng et al., 2000).

Experimental design and optimization by RSM: The conventional one-factor-at-a-time method was used to select the effective factors and the initial test range of each of five variables: substrate concentration (A), inoculum volume (B), incubation time (C), initial moisture (D) and initial $\mathrm{pH}(\mathrm{E})$. Taking these factors (independent parameters) into consideration, a response surface methodology using central composite design (CCD) was adopted for improving red pigment production from $P$. purpurogenum. The statistical software package Design-Expert 8.0 was used to analyze the experimental design. A 25 factorial central composite experimental design, with five factors and eight replicates at the centre point, leading to a set of 50 
C. Padmapriya and R. Murugesan / J. Appl. \& Nat. Sci. 8(3): 1663 - 1669 (2016)

Table 2. Central composite rotatable design matrix of fermentation parameters of independent variables and corresponding experimental yields of red pigment.

\begin{tabular}{|c|c|c|c|c|c|c|c|}
\hline \multirow{2}{*}{$\begin{array}{l}\text { Run } \\
\text { No. }\end{array}$} & \multirow{2}{*}{$\begin{array}{l}\text { Substrate concentration } \\
\text { (g) }\end{array}$} & \multirow{2}{*}{$\begin{array}{l}\text { Inoculum vol- } \\
\text { ume (ml) }\end{array}$} & \multirow{2}{*}{$\begin{array}{c}\text { Incubation time } \\
\text { (days) }\end{array}$} & \multirow{2}{*}{$\begin{array}{l}\text { Moisture } \\
(\%)\end{array}$} & \multirow{2}{*}{ pH } & \multicolumn{2}{|c|}{ Pigment yield $\left(\mathrm{CVU}\right.$ gds $\left.^{-1}\right)$} \\
\hline & & & & & & Observed & Predicted \\
\hline 1 & +1 & +1 & -1 & -1 & +1 & 12.92 & 13.65 \\
\hline 2 & +1 & -1 & -1 & -1 & +1 & 15.45 & 16.52 \\
\hline 3 & -1 & -1 & -1 & -1 & +1 & 11.77 & 12.65 \\
\hline 4 & +1 & -1 & +1 & +1 & -1 & 14.87 & 15.14 \\
\hline 5 & +1 & +1 & +1 & +1 & +1 & 11.27 & 11.60 \\
\hline 6 & -1 & +1 & +1 & +1 & -1 & 13.56 & 14.33 \\
\hline 7 & +1 & -1 & +1 & +1 & +1 & 11.43 & 12.03 \\
\hline 8 & -1 & +1 & -1 & -1 & +1 & 13.97 & 14.39 \\
\hline 9 & +1 & -1 & -1 & -1 & -1 & 13.94 & 14.81 \\
\hline 10 & -1 & -1 & -1 & +1 & -1 & 13.17 & 13.76 \\
\hline 11 & -1 & +1 & -1 & +1 & -1 & 12.97 & 13.78 \\
\hline 12 & +1 & -1 & -1 & +1 & -1 & 12.85 & 12.35 \\
\hline 13 & +1 & +1 & +1 & +1 & -1 & 16.54 & 17.02 \\
\hline 14 & -1 & -1 & -1 & -1 & -1 & 15.73 & 15.83 \\
\hline 15 & -1 & +1 & +1 & -1 & +1 & 15.38 & 17.42 \\
\hline 16 & +1 & -1 & -1 & +1 & +1 & 14.77 & 15.86 \\
\hline 17 & +1 & -1 & +1 & -1 & -1 & 17.54 & 17.57 \\
\hline 18 & -1 & +1 & +1 & +1 & +1 & 22.31 & 22.26 \\
\hline 19 & -1 & +1 & -1 & +1 & +1 & 17.12 & 17.16 \\
\hline 20 & +1 & -1 & +1 & -1 & +1 & 21.17 & 21.48 \\
\hline 21 & -1 & -1 & +1 & +1 & -1 & 13.20 & 13.34 \\
\hline 22 & +1 & +1 & -1 & +1 & -1 & 17.24 & 17.89 \\
\hline 23 & -1 & +1 & -1 & -1 & -1 & 13.76 & 14.36 \\
\hline 24 & +1 & +1 & -1 & -1 & -1 & 18.65 & 18.54 \\
\hline 25 & -1 & -1 & +1 & -1 & -1 & 13.77 & 13.24 \\
\hline 26 & -1 & +1 & +1 & -1 & -1 & 14.33 & 14.01 \\
\hline 27 & +1 & +1 & -1 & +1 & +1 & 11.87 & 12.80 \\
\hline 28 & -1 & -1 & +1 & -1 & +1 & 12.37 & 13.20 \\
\hline 29 & -1 & -1 & +1 & +1 & +1 & 12.78 & 13.26 \\
\hline 30 & +1 & +1 & +1 & -1 & -1 & 13.68 & 13.89 \\
\hline 31 & +1 & +1 & +1 & -1 & +1 & 14.23 & 14.26 \\
\hline 32 & -1 & -1 & -1 & +1 & +1 & 14.51 & 14.54 \\
\hline 33 & 0 & $-\alpha$ & 0 & 0 & 0 & 10.23 & 9.54 \\
\hline 34 & 0 & $+\alpha$ & 0 & 0 & 0 & 12.87 & 13.25 \\
\hline 35 & 0 & 0 & 0 & 0 & $-\alpha$ & 16.04 & 16.04 \\
\hline 36 & $-\alpha$ & 0 & 0 & 0 & 0 & 14.10 & 15.59 \\
\hline 37 & 0 & 0 & $+\alpha$ & 0 & 0 & 13.10 & 13.63 \\
\hline 38 & $+\alpha$ & 0 & 0 & 0 & 0 & 12.44 & 12.76 \\
\hline 39 & 0 & 0 & 0 & 0 & $+\alpha$ & 14.77 & 15.01 \\
\hline 40 & 0 & 0 & 0 & $+\alpha$ & 0 & 11.44 & 11.60 \\
\hline 41 & 0 & 0 & $-\alpha$ & 0 & 0 & 11.88 & 12.17 \\
\hline 42 & 0 & 0 & 0 & $-\alpha$ & 0 & 17.33 & 15.23 \\
\hline 43 & 0 & 0 & 0 & 0 & 0 & 28.10 & 28.33 \\
\hline 44 & 0 & 0 & 0 & 0 & 0 & 27.54 & 28.33 \\
\hline 45 & 0 & 0 & 0 & 0 & 0 & 27.32 & 28.33 \\
\hline 46 & 0 & 0 & 0 & 0 & 0 & 28.35 & 28.33 \\
\hline 47 & 0 & 0 & 0 & 0 & 0 & 27.92 & 28.33 \\
\hline 48 & 0 & 0 & 0 & 0 & 0 & 28.17 & 28.33 \\
\hline 49 & 0 & 0 & 0 & 0 & 0 & 27.53 & 28.33 \\
\hline 50 & 0 & 0 & 0 & 0 & 0 & 27.92 & 28.33 \\
\hline
\end{tabular}


experiments, was used to optimize the production of red pigment from $P$. purpurogenum. All the variables were taken at a central coded value considered as zero. The minimum and maximum ranges of variables investigated and the full experimental plan with respect to their values in actual and coded form are listed in Table 1. The average maximum red pigment production was taken as the dependent variable or response (Y). Regression analysis was performed on the data obtained. The results of a CCD were used to fit a second-order polynomial equation represented as:

$Y=\beta 0+\beta 1 A+\beta 2 B+\beta 3 C+\beta 4 D+\beta 5 E+\beta 12 A B+$ $\beta 13 \mathrm{AC}+\beta 14 \mathrm{AD}+\beta 15 \mathrm{AE}+\beta 23 \mathrm{BC}+\beta 24 \mathrm{BD}+$ $\beta 25 \mathrm{BE}+\beta 34 \mathrm{CD}+\beta 35 \mathrm{CE}+\beta 45 \mathrm{DE}$.

Where; $\mathrm{Y}=$ Predicted response, $\beta 0=$ Regression coefficient, $\quad \beta 1 \beta 2 \beta 3 \beta 4 \beta 5=$ Linear coefficients, $\beta 12 \beta 13 \beta 14 \beta 15 \beta 23 \beta 24 \beta 25 \beta 34 \beta 35 \beta 45=$ Interaction coefficients.

The pigment production was observed from each of 50 experiments analysed by Analysis of variance (ANOVA) to determine the optimum condition. The proportion of variance explained by the polynomial models obtained was given by the multiple coefficient of determination, $\mathrm{R}^{2}$.

\section{RESULTS AND DISCUSSION}

Interaction of factors and red pigment production: Substrate $\mathrm{pH}$ is one of the important factors determining microbial growth and metabolic activity in SSF. In this study, red pigment production was maximal at substrate $\mathrm{pH}$ 6. Pigment production was reduced at $\mathrm{pH}$ 6.5 , and was completely inhibited with further increases in $\mathrm{pH}$. These results are consistent with Babitha et al. (2007) who reported maximum pigment production by Monasus purpureus at $\mathrm{pH} 4.5$ to 7.5. A lower substrate $\mathrm{pH}$ promotes synthesis of yellow pigments, whereas a higher $\mathrm{pH}$ results in red pigments (Orozco and Kiikian, 2008 ). The red pigment yield increased upon increasing the concentration of cassava waste (up to $10 \mathrm{~g}$ ) and decreasing the moisture content of the substrate to $50 \%$. High levels of pigment production with increase in cassava waste concentration could be due to the fact that cassava waste is a nutrient rich substrate for pigment producing microorganisms since it contains starch, cellulose, hemicelluloses, pectin, fiber and protein which promote the fungal growth

Table 3. ANOVA for red pigment production by SSF using CCD.

\begin{tabular}{lccccc}
\hline Source & $\begin{array}{c}\text { Sum of } \\
\text { Squares }\end{array}$ & $\begin{array}{c}\text { Degree of } \\
\text { Freedom }\end{array}$ & Mean Square & F-value & Significance- $\boldsymbol{F}$ \\
\hline Model & 1490.12 & 20 & 74.51 & 226.06 & $<0.0001$ \\
A-Substrate concentration & 27.40 & 1 & 27.40 & 83.13 & $<0.0001$ \\
B-Inoculum volume & 2.46 & 1 & 2.46 & 7.47 & 0.0106 \\
C-Incubation time & 1.98 & 1 & 1.98 & 6.01 & 0.0205 \\
D-Moisture & 22.52 & 1 & 22.52 & 68.32 & $<0.0001$ \\
E-pH & 38.68 & 1 & 38.68 & 117.37 & $<0.0001$ \\
$\mathrm{~A}^{2}$ & 482.48 & 1 & 482.48 & 1463.89 & $<0.0001$ \\
$\mathrm{~B}^{2}$ & 300.22 & 1 & 300.22 & 910.89 & $<0.0001$ \\
$\mathrm{C}^{2}$ & 414.44 & 1 & 414.44 & 1257.44 & $<0.0001$ \\
$\mathrm{D}^{2}$ & 396.66 & 1 & 396.66 & 1203.50 & $<0.0001$ \\
$\mathrm{E}^{2}$ & 321.83 & 1 & 321.83 & 976.46 & $<0.0001$ \\
Residual & 9.56 & 29 & 0.33 & - & - \\
Lack of fit & 8.33 & 22 & 0.38 & 2.16 & 0.1496 \\
Pure error & 1.23 & 7 & 0.18 & & \\
Corrected total & 1499.68 & 49 & & & \\
$\mathrm{R}^{2}=0.9936$ & & & Adjusted R ${ }^{2}=0.9892$ & & \\
\hline
\end{tabular}

Table 4. Significance of the regression coefficients of the model.

\begin{tabular}{lcccc}
\hline Factor & Regression Co efficient & Degrees of freedom & Standard error & P value \\
\hline Intercept & 27.87 & 1 & 0.20 & $<0.0001$ \\
A-Substrate concentration & 0.80 & 1 & 0.087 & $<0.0001$ \\
B-Inoculum volume & -0.24 & 1 & 0.087 & 0.0106 \\
C-Incubation time & -0.21 & 1 & 0.087 & 0.0205 \\
D-Moisture & -0.72 & 1 & 0.087 & $<0.0001$ \\
E-pH & 0.95 & 1 & 0.087 & $<0.0001$ \\
A-A & -2.95 & 1 & 0.077 & $<0.0001$ \\
B-B & -2.32 & 1 & 0.077 & $<0.0001$ \\
C-C & -2.73 & 1 & 0.077 & $<0.0001$ \\
D-D & -2.61 & 1 & 0.077 & $<0.0001$ \\
E-E & -2.41 & 1 & 0.077 & $<0.0001$ \\
\hline
\end{tabular}


C. Padmapriya and R. Murugesan / J. Appl. \& Nat. Sci. 8(3): 1663 - 1669 (2016)
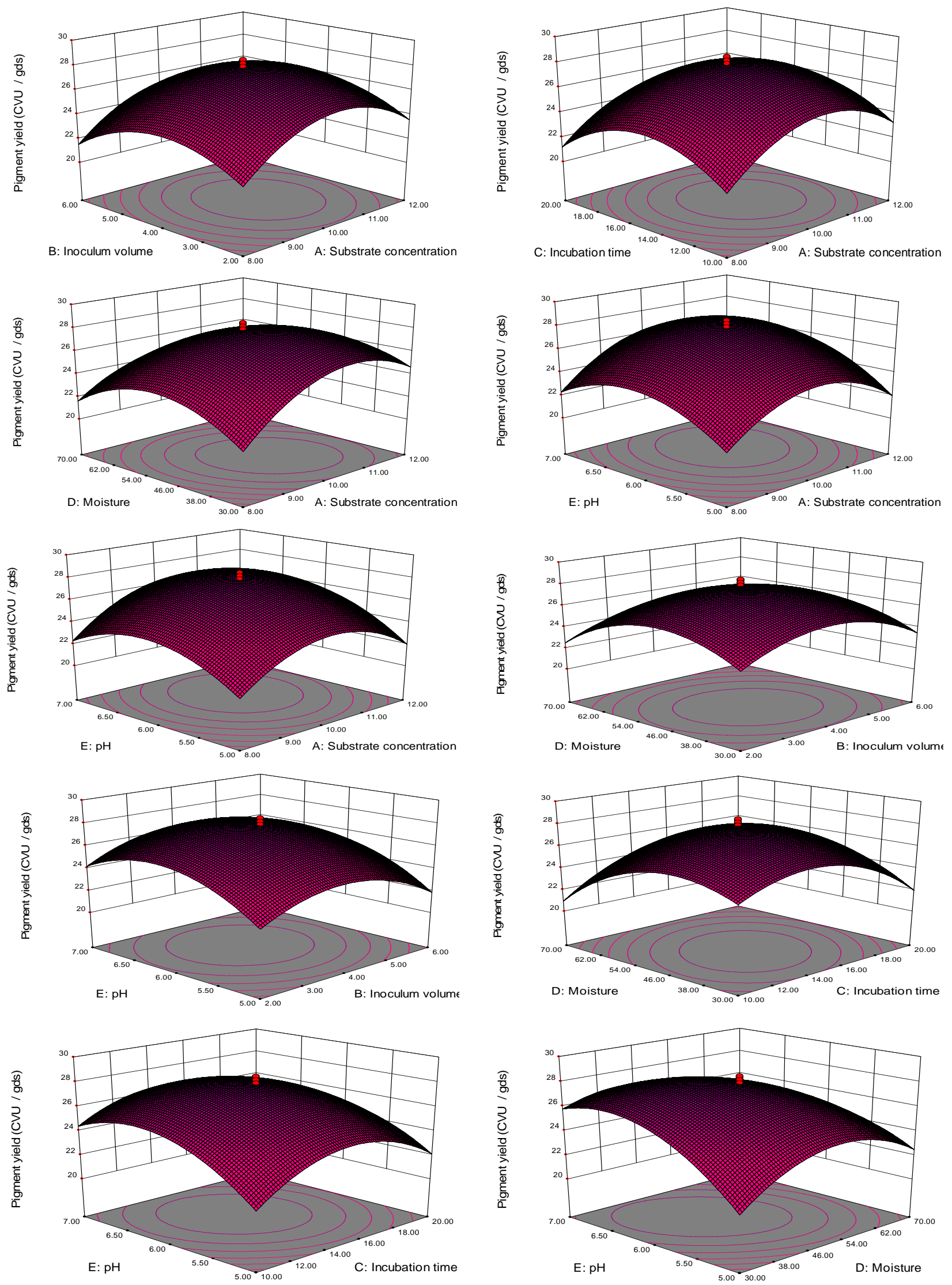

Fig 1. Response surface curve showing the effect of SSF parameters on red pigment production. 
and thereby increase the pigment yield. However, decline in pigment production at higher concentration of cassava waste levels ( $12 \mathrm{~g})$ could be due to substrate inhibition.

For SSF, moisture is a key parameter to control the growth of microorganism and metabolite production (Pandey, 2003). This can be attributed to effective utilization of sugars in the substrate. In this study, the red pigment yield was reduced above or below $50 \%$ moisture content of cassava waste. It may be concluded that $50 \%$ moisture content of the substrate was optimum for red pigment production. This result was similar to the findings of Vemurugan et al., (2011) who reported that initial substrate moisture content less than $40 \%$ gave less pigmentation, but that of 50-60\% could give the highest pigmentation. Higher initial moisture in SSF leads to suboptimal product formation due to reduced mass transfer process and decrease in initial moisture level results in reduced solubility minimizes heat exchange, oxygen transfer and low availability of nutrients to the culture ( Babitha et al., 2007 ).

Pigment production significantly increased up to an inoculum volume of $4 \mathrm{ml}$ of spores per gram of initial dried substrate (spores $\mathrm{gds}^{-1}$ ). Higher inoculum of 4.5 $\mathrm{ml}$ of spores $\mathrm{gds}^{-1}$ produced too much biomass with less pigment yield. A low inoculum density of $2 \mathrm{ml}$ spores $\mathrm{gds}^{-1}$ resulted in insufficient biomass causing reduced product formation, whereas higher inoculum of $6.0 \mathrm{ml}$ spores $\mathrm{gds}^{-1}$ produced too much biomass and depleted the substrate of nutrients required for pigment production (Babitha et al., 2007). The amount of pigment production varied with incubation time. Maximum red pigment production was obtained after 15 days of incubation. Pigment production was decreased from $20^{\text {th }}$ to $30^{\text {th }}$ day, likely due to the decline or death phase of the fungus. The depletion of essential nutrients present in the substrate and the accumulation of inhibitory products such as acids decreased the fungal growth and red pigment production after 30 days of incubation.

The three dimensional response surfaces were plotted to study the interaction among the various factors (substrate concentration, inoculum volume, incubation time, initial moisture and initial $\mathrm{pH}$ ) selected and to determine the optimum concentration for attaining maximum red pigment production. The plots were generated by plotting the response using the $\mathrm{z}$-axis against two independent variables while keeping the other independent variables at their O-level. The coordinates of the central point within the highest contour levels in each of the figures correspond to the optimum concentrations of the respective components. The response surface plots with $3 \mathrm{D}$ response surface of the calculated model are shown in Fig.1 which indicates the relationship between the response and the experimental data.
RSM analysis for red pigment production: The results of CCD experiments for studying the effect of five independent variables are presented along with the mean predicted and observed responses in Table 2 . The regression equations obtained after the ANOVA gave the level of red pigment production as a function of the initial values of substrate concentration, inoculum volume, incubation time, initial moisture and initial $\mathrm{pH}$. The final response equation that represented a suitable model for red pigment production is given below:

$\mathrm{Y}=+28.33+0.80 \mathrm{~A}-0.24 \mathrm{~B}-0.21 \mathrm{C}-0.72 \mathrm{D}+0.95 \mathrm{E}+$ $0.036 \mathrm{AB}-0.033 \mathrm{AC}-0.88 \mathrm{AD}+0.37 \mathrm{AE}+0.35 \mathrm{C}-$ $0.13 \mathrm{~B} D+0.11 \mathrm{~B} \mathrm{E}+1.01 \mathrm{C} \mathrm{D}-0.53 \mathrm{CE}-1.36 \mathrm{DE}-$ $2.95 \mathrm{~A} 2-2.32 \mathrm{~B} 2-2.73 \mathrm{C} 2-2.67 \mathrm{D} 2-2.41 \mathrm{E} 2$

Where; Y pigment production, A substrate concentration, B inoculum volume, $\mathrm{C}$ incubation time, $\mathrm{D}$ initial moisture and $\mathrm{E}$ initial $\mathrm{pH}$.

The regression equation indicated that coefficient of determination $\left(\mathrm{R}^{2}\right)$ was 0.9936 (a value of $\mathrm{R}^{2}>0.75$ indicates the aptness of the model) for red pigment production (Table 3). The $\mathrm{R}^{2}$ value is always between 0 and 1 . The closer the $\mathrm{R}^{2}$ is to 1.0 , the stronger the model and the better it predicts. Moreover, $\mathrm{R}^{2}$ is in reasonable agreement with adjusted $\mathrm{R}^{2}$ of 0.9892 . The $\mathrm{R}^{2}$ value provided a measure of variability in the observed response values, which could be explained by the experimental factors and their interactions. The adjusted $R^{2}$ corrects the $R^{2}$ value for the sample size and number of terms in the model. If there are many terms in the model and the sample size is not very large, the adjusted $\mathrm{R}^{2}$ may be noticeably smaller than predicted $\mathrm{R}^{2}$. The purpose of statistical analysis is to determine the experimental factors, which generate signals that are large in comparison to noise. The adequate precision measuring the signal to noise ratio was found to be 49.885. A signal to noise ratio greater than 4 is desirable. The model is thus fit and could be used to navigate the design space. The predicted sum of squares (PRESS), which is a measure of how particular model fits each point in design, was 34.23.

The computed $F$-value (226.06), which is the ratio of mean square due to regression to the mean square due to error and indicates the influence (significant or not) of each controlled factor on tested model was significant at high confidence level. The low probability pvalue $(<0.05)$ indicated that model terms are significant (Table 4). For red pigment production, A, B, C, D, $\mathrm{E}, \mathrm{AD}, \mathrm{AE}, \mathrm{BC}, \mathrm{CD}, \mathrm{CE}, \mathrm{DE}, \mathrm{A} 2, \mathrm{~B} 2, \mathrm{C} 2, \mathrm{D} 2$ and $\mathrm{E} 2$ are significant model terms.

\section{Conclusion}

This study optimized the red pigment yield using RSM. It is evident that the use of statistical process condition optimization approach, response surface methodology has helped to locate the most significant 
conditions with minimum effort and time. In addition, it has also proved to be useful in increasing pigment yield. Only 50 experiments were necessary and the obtained model was adequate $(\mathrm{P}<0.001)$. By solving the regression equation, under the optimum process conditions viz. $10 \mathrm{~g}$ (substrate concentration), $4 \mathrm{ml}$ (inoculum volume), 15 days (incubation time), 50\% (initial moisture content) and $\mathrm{pH} 6$, a maximum pigment yield of $28.33 \mathrm{CVU}_{\text {gdfs }^{-1}}$ was obtained at the optimized process conditions. The results of our study indicate the feasibility and applicability of cassava waste, sago industry by-product, for production of red pigment from $P$. purpurogenum by SSF. Cassava waste is an economical and environmentally safe to end users. In recent years, production of natural food colourants through microbial fermentation is an extensive area of investigation, since they overcome concerns of unfavourable side effects by synthetic colours. The pigment produced by P.purpurogenum. indicated its importance in food, textile, pharmaceutical and nutraceuticals industries.

\section{ACKNOWLEDGEMENTS}

The authors kindly acknowledge the funding granted by Indian council of Agricultural Research (ICAR) under the scheme "Application of microorganisms in Agriculture and allied sciences (AMAAS)".

\section{REFERENCES}

Babitha, S., Soccol, C. R. and Pandey, A. (2007). Solid-state fermentation for the production of Monascus pigments from jackfruit seed. Bioresource Technology, 98: 1554 -1560 .

Dufosse, L. (2006). Microbial production of food grade pigments. Food Technology and Biotechnoogy, 44: 313321.

Fabre, C.E., Santerre, A.L., Loret, M.O., Baberian, R., Paresllerin, A., Goma, G. and Blanc, P.J. (1993). Production and food applications of the red pigments of Monascus ruber. Journal of Food Science, 58: 10991110.

Haltrich, D., Press, M. and Steiner, W. (1993). Optimization of a culture medium for increased xylanase production by a wild strain of Schizophyllum commune. Enzyme and Microbial Technology, 15: 854-860.

Juzlova, P., Martinkova, L. and Kren, V. (1996). Secondary metabolites of the fungus Monascus: A review. Journal of Industrial Microbiology, 16: 163-170.

Karuppaiya, M., Sasikumar, E., Viruthagiri, T. and Vijay- agopal, V. (2009). Optimization of process conditions using Response Surface Methodology (RSM) for ethanol production from waste cashew apple juice by Zymomonas mobilis. Chemical Engineering Communications, 196: 1425-1435.

Karuppaiya,M., Sasikumar, E., Viruthagiri, T. and Vijayagopal, V. (2010). Optimization of process variables using response surface methodology (RSM) for ethanol production from cashew apple juice by Saccharomyces cerevisiae. Asian Journal of Food and Agro-Industry, 3 (04): 462-473.

Liu, B.H., Wu, T.S., Su, M.C., Chung, C.P. and Yu, F.Y. (2005). Evaluation of Citrinin occurrence and cytotoxicity in monascus fermentation products. Journal of Agricultural and Food Chemistry, 53: 170-175.

Mapari, S.A.S., Hansen, M.E., Meyer, A.S. and Thrane, U. (2008). Computerized screening for novel producers of Monascus like food pigments in Penicillium species. Journal of Agricultural and Food Chemistry, 56: 99819989.

Marlin, U., Gagel, U., Popel, O., Bernstein, S. and Rosenthal, I. (1987). Thermal degradation kinetics of prickly pear fruit red pigments. Journal of Food Science, 52: 485-486.

Orozco, S.F. and Kilikian, B.V. (2008). Effect of pH on citrinin and red pigments production by Monascus purpureus CCT3802. Word Journal of Microbioogy and Biotechnoogy, 24(2): 263-268.

Pandey, A. (2003). Solid-state fermentation. Biochemical Engineering Journal, 14: 81-84.

Parekh, S., Vinci, V.A. and Strobel, R.J. (2000). Improvement of microbial strains and fermentation processes. Applied Microbiology and Biotechnology, 54: 287-301.

Pattanagul, P., Pinthong, R., Phianmongkhol, A. and Leksawasdi, N. (2007). Review of Angkak Production (Monascus purpureus). Chiang Mai Journal of Science, 34: 319-328.

Prapulla, S.G., Jacob, S., Chand, N., Rajalakshmi, D. and Karanth, N.G. (1992). Maximization of lipid production by Rhodotroula gracilis CFR-1 using response surface methodology, Biotechnology and Bioengineering, 40: 965-969.

Tseng, Y.Y., Chen, M.T. and Lin, C.F. (2000). Growth, pigment production and protease activity of Monascus purpureus as affected by salt, sodium nitrite, polyphosphate and various sugars. Journal of Applied Microbiology, 88: 31-37.

Velmurugan, P., Hur, H., Balachandar, V., Kamala-Kannan, S., Lee, K. J., Lee, S.M., Chae, J.C., Shea, P. J. and Oh, B.T. (2011). Monascus pigment production by solid -state fermentation with corn cob substrate. Journal of Bioscience and Bioengineering, 112: 590-594. 